\title{
Targeting $\beta_{3}$-Adrenergic Receptors in the Heart: Selective Agonism and $\beta$-Blockade
}

\author{
Alessandro Cannavo, PhD and Walter J. Koch, PhD
}

\begin{abstract}
Cardiac diseases, such as heart failure, remain leading causes of morbidity and mortality worldwide, with myocardial infarction as the most common etiology. HF is characterized by $\beta$-adrenergic receptor ( $\beta \mathrm{AR}$ ) dysregulation that is primarily due to the upregulation of $\mathrm{G}$ protein-coupled receptor kinases that leads to overdesensitization of $\beta_{1}$ and $\beta_{2} \mathrm{ARs}$, and this clinically manifests as a loss of inotropic reserve. Interestingly, the "minor" $\beta A R$ isoform, the $\beta_{3} \mathrm{AR}$, found in the heart, lacks $\mathrm{G}$ protein-coupled receptor kinases recognition sites, and is not subject to desensitization, and as a consequence of this, in human failing myocardium, the levels of this receptor remain unchanged or are even increased. In different preclinical studies, it has been shown that $\beta_{3}$ ARs can activate different signaling pathways that can protect the heart. The clinical relevance of this is also supported by the effects of $\beta$-blockers which are well known for their proangiogenic and cardioprotective effects, and data are emerging showing that these are mediated, at least in part, by enhancement of $\beta_{3} \mathrm{AR}$ activity. In this regard, targeting of $\beta_{3}$ ARs could represent a novel potential strategy to improve cardiac metabolism, function, and remodeling.
\end{abstract}

Key Words: $\beta$-adrenergic receptor, $G$ proteins, heart failure, $\beta$-blockers

(J Cardiovasc Pharmacol ${ }^{\mathrm{TM}}$ 2017;69:71-78)

\section{INTRODUCTION}

G protein-coupled receptors (GPCRs) are nodal regulators of mammalian cell physiology because they transduce cell signals from diverse ligands such as neurohormones, sensory stimuli, and ions through heterotrimeric $\mathrm{G}$ proteins. ${ }^{1}$ In the heart, they represent the major

Received for publication August 29, 2016; accepted October 16, 2016.

From the Department of Pharmacology, Center for Translational Medicine, Lewis Katz School of Medicine, Temple University, Philadelphia, PA. Supported by American Heart Association 16POST30980005 (A.C.).

The authors report no conflicts of interest.

Reprints: Walter J. Koch, PhD, W.W. Smith, Chair in Cardiovascular Medicine, Department of Pharmacology, Center for Translational Medicine, Lewis Katz School of Medicine, Temple University, 3500 North Broad St, MERB 941, Philadelphia, PA 19140 (e-mail: walter. koch@temple.edu).

Copyright (C 2016 The Author(s). Published by Wolters Kluwer Health, Inc. This is an open-access article distributed under the terms of the Creative Commons Attribution-Non Commercial-No Derivatives License 4.0 (CCBY-NC-ND), where it is permissible to download and share the work, provided it is properly cited. The work cannot be changed in any way or used commercially without permission from the journal. modulators of both function and morphology with $\beta$-adrenergic receptors ( $\beta$ ARs) representing "the heads of the line", and for this reason they are considered the most important molecular targets in the cardiovascular system. ${ }^{2-4}$ Currently, $3 \beta$ AR subtypes $\left(\beta_{1} \mathrm{AR}, \beta_{2} \mathrm{AR}\right.$, and $\beta_{3} \mathrm{AR}$ ) have been identified in the myocardium, with $\beta_{1}$ and $\beta_{2}$ ARs the most expressed and studied. ${ }^{5-7}$ However, since its discovery in $1989,{ }^{7}$ it soon seemed clear that $\beta_{3} \mathrm{ARs}$, the isoform with minor expression, can influence cardiovascular physiology. In particular, $\beta_{3}$ ARs seem to have multiple roles that go from regulation of metabolism, ${ }^{8,9}$ vasodilation, and relaxation ${ }^{8}$ to cardiac contractility. ${ }^{9}$ Thus, this receptor is of high interest especially for new potential therapeutic approaches for heart disease.

In this review, we will discuss what is known about the cardiac role of $\beta_{3}$ ARs and how not only their activation but also the blockade could be beneficial or not in cardiac physiology and in disease.

\section{$\beta_{3}$-Adrenergic Receptor $\left(\beta_{3} A R\right)$ Structure}

The mammalian $\beta_{3}$ AR sequence consists of about 400-408 amino acids in a protein that has the typical structure of all GPCRs. ${ }^{10}$ The $\beta_{3}$ AR has 7 transmembrane domains (7-TMDs) with an extracellular N-terminal that is glycosylated, and an intracellular C-terminal domain. ${ }^{10}$ Further, the Cys361 residue in the fourth intracellular domain is palmitoylated, a feature that has been shown to be associated with $G$ protein-coupling and adenylyl cyclase stimulation following agonist stimulation of the receptor $^{11}$ (Fig. 1). As shown in Figure 2, the protein sequence alignment between different mammalian species demonstrates that most of the homology between the $\beta_{3} \mathrm{AR}$ amino acid sequences is concentrated in the 7-TMDs and in the membrane-proximal regions of the intracellular loops. Interestingly, when the $\beta_{3} \mathrm{AR}$ protein sequence is compared with other $\beta \mathrm{AR}\left(\beta_{1}\right.$ and $\left.\beta_{2} \mathrm{AR}\right)$ isoforms, it is still possible to observe a high level of homology in the 7-TMD sequence, but a significant divergence is present both in the third intracellular loop and in the C-terminal domain (Fig. 3). This difference probably represents the major factor affecting the pharmacologic regulation of the receptors and their response to a ligand. In this regard, the C-terminus of both $\beta_{1}$ and $\beta_{2} \mathrm{ARs}$ is rich in serine and threonine residues, and is subjected to GPCR kinase (GRK)mediated regulation through phosphorylation. ${ }^{10}$ Further, these receptors also harbor a consensus sequence for protein kinase A (PKA). ${ }^{10}$ Of note, the $\beta_{3}$ AR lacks all of these sites, and is more resistant to agonist-induced desensitization/ 
FIGURE 1. Human $\beta_{3} A R$ structure. Shown here is the structure of the human $\beta_{3} A R$. The receptor is a GPCR with 7-TMDs, an extracellular $\mathrm{N}$-terminal domain (exD1), and an intracellular C-terminal domain (inD4). The receptor presents also 6 loops, 3 are intracellular (inD1, inD2, and inD3), and 3 are extracellular (exD2, exD3, and exD4). Indicated with arrows are the asparagine $(\mathrm{N})$ residues, in the exD1, that are sites of $\mathrm{N}$-glycosylation; tryptophan (W) in position 64 that is the location of $\beta_{3}$ AR-polymorphism (Trp64Arg) and the cysteine (C) in position 361 that is a site subjected to palmitoylation.

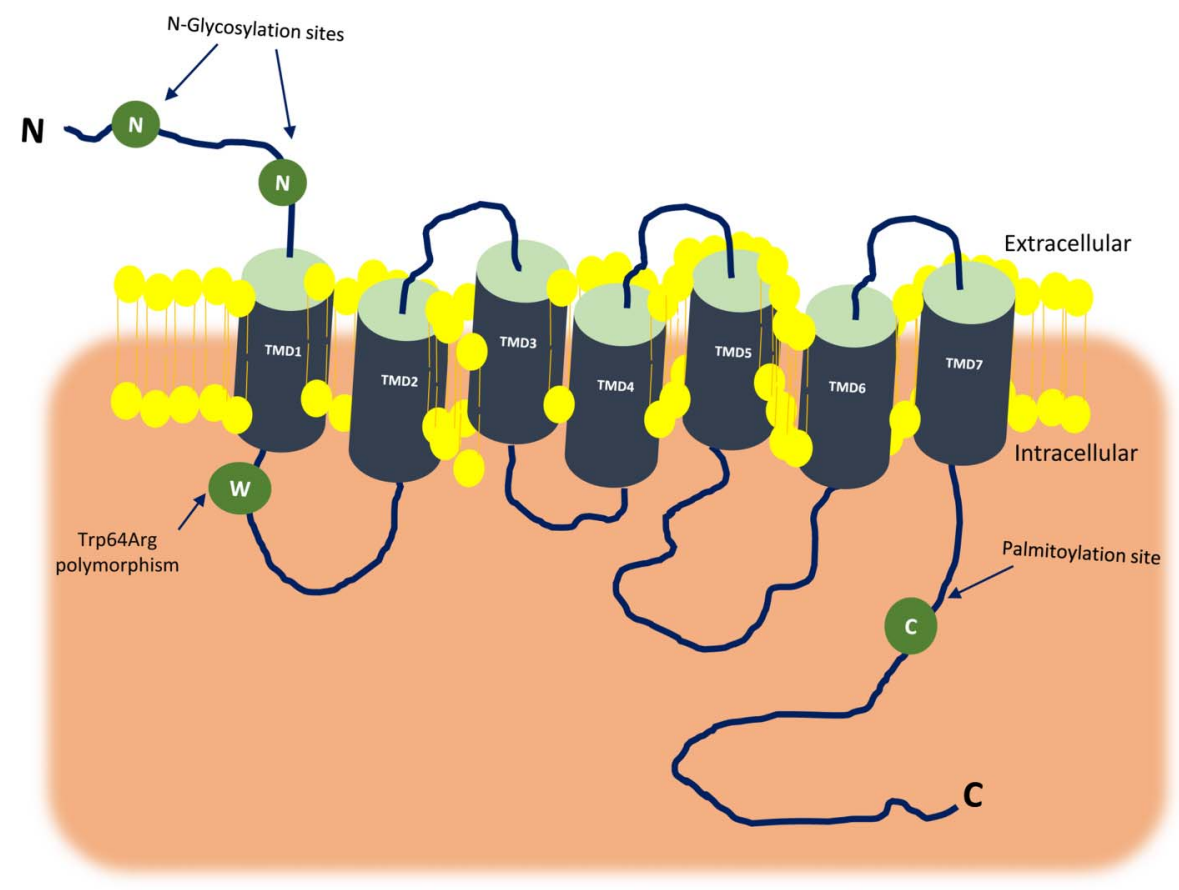

downregulation. Finally, these sequence divergences also support differential and intracellular signaling (including $\mathrm{G}$ protein-coupling) between the $3 \beta \mathrm{AR}$ isoforms, which may determine their relative roles in physiology and in the disease.

\section{$\beta_{3} A R$ : in Search of Signaling and Function}

The human $\beta_{3}$ AR was cloned in $1989,{ }^{7}$ and the studies demonstrated that this new $\beta$ AR isoform was mainly implicated in lipolysis and thermogenesis regulation in adipose tissues. ${ }^{8,12}$ However, over the last 2 decades, different reports have also clearly shown that $\beta_{3}$ ARs are present in the cardiovascular system, mainly in myocardium and endothelium, where they have a prominent role in modulating cardiac function and angiogenesis, respectively. ${ }^{13,14}$ In this context, determining the specific pathways associated with these effects represents a tough challenge and remains a largely unresolved question regarding $\beta_{3} \mathrm{AR}$ function. This is due, at least in part, to the fact that the role of the cardiac $\beta_{3} \mathrm{AR}$ has not been studied with the same intensity as the $\beta_{1}$ - and $\beta_{2}$ ARs. Moreover, all the studies concerning $\beta_{3} A R$ function have not been focused on similar cell types, and the agonist and the doses used are significantly different between most studies. ${ }^{14,15}$ Another important difference is represented by the experimental model used in key studies. ${ }^{15}$ In fact, it is known that in the mouse, the gene encoding for the $\beta_{3} \mathrm{AR}$ undergoes alternative splicing and gives rise to $\beta_{3} \mathrm{aAR}$ and $\beta_{3} \mathrm{bAR}$ variants. . $^{16,17}$ These $2 \beta_{3} \mathrm{AR}$ isoforms are coupled to adenylyl cyclase stimulatory $\mathrm{G} \alpha(\mathrm{G} \alpha \mathrm{s})$ or to the inhibitory $\mathrm{G} \alpha(\mathrm{G} \alpha \mathrm{i})$ protein subunits $\left(\beta_{3} \mathrm{bAR}\right)$, or exclusively to the $\mathrm{G} \alpha$ s protein $\left(\beta_{3} \mathrm{aAR}\right) \cdot{ }^{17,18}$ By contrast, in humans, although some reports have proposed that $\beta_{3} \mathrm{AR}$ can activate $\mathrm{G} \alpha \mathrm{s}$ signaling in $\mathrm{CHO} / \mathrm{K} 1$ cells $^{19}$ and in adipocytes ${ }^{20}$ it is a general assumption that, at least in ventricular myocardium, $\beta_{3}$ ARs are mainly coupled with G $\propto$ i proteins..$^{21,22}$

For these reasons, the $\beta_{3} \mathrm{AR}$ leads to effects that are either comparable or opposite to those elicited by $\beta_{1}$ - and $\beta_{2} \mathrm{AR}$ stimulation. In fact, stimulation of $\beta_{3} \mathrm{AR}$, through Gas activation, increases the generation of cyclic AMP (cAMP) and the activation of the PKA, similar to $\beta_{1}$ - and $\beta_{2}$ ARs. $^{4,23}$ In the myocardium, after catecholamines stimulation of $\beta$ ARs, PKA phosphorylates many $\mathrm{Ca}^{2+}$ handling proteins and some myofilament components leading to positive inotropic, lusitropic, and chronotropic effects $^{4,23}$ (Fig. 4). However, because $\beta_{3}$ ARs are also coupled with Gai, they can act as a brake to prevent $\beta_{1}$ and $\beta_{2} \mathrm{ARs}$ overactivation, and this has been proposed as a mechanism in the heart ${ }^{21,22}$ (Fig. 4). Moreover, in the heart, the stimulation of $\beta_{3}$ ARs leads to increased endothelial nitric oxide (NO) synthase (eNOS) $)^{22,24}$ or neuronal (nNOS) activation, ${ }^{25,26}$ giving rise to NO generation and activation of soluble guanylate cyclase to produce cGMP and cGMP-dependent protein kinase G (PKG) activation $^{25-27}$ (Fig. 4). PKG is a serine/threonine kinase that mediates many of the biological effects of NO/cGMP. ${ }^{28,29}$ In particular, PKG downstream of $\beta_{3}$ ARs can enhance myocytes relaxation but cause negative inotropy, possibly through the phosphorylation of troponin I and L-type $\mathrm{Ca}^{2+}$ channel $^{26-29}$ (Fig. 4). Importantly, the $\beta_{3} \mathrm{AR} / \mathrm{NO}-\mathrm{cGMP} /$ PKG signaling axis seems to be a robust cardioprotective mechanism that can be beneficial in failing myocardium. ${ }^{22,26,29}$ In fact, PKG activation downstream of cGMP has been proven to reduce $\mathrm{Ca}^{2+}$ oscillations which can cause ventricular arrhythmias, hypercontracture and sarcolemmal rupture as well as mitochondrial 
$\beta_{3}$ aAR-MOUSE
$\beta_{3}$ bAR-MOUSE
$\beta_{3}$ AR-DOG
$\beta_{3}$ AR-PIG
$\beta_{3}$ AR-HUMAN
$\beta_{3}$ AR-MACACA

$\beta_{3}$ aAR-MOUSE

$\beta_{3}$ bAR-MOUSE

$\beta_{3} A R-D O G$

$\beta_{3} \mathrm{AR}-\mathrm{PIG}$

$\beta_{3} A R-H U M A N$

$\beta_{3} \mathrm{AR}-\mathrm{MACACA}$

$\beta_{3}$ aAR-MOUSE

$\beta_{3}$ DAR-MOUSE

$\beta_{3} A R-D O G$

$\beta_{3}$ AR-PIG

$\beta_{3}$ AR-HUMAN

$B_{3} \mathrm{AR}-\mathrm{MACACA}$

$\beta_{3}$ aAR-MOUSE

$\beta_{3}$ bAR-MOUSE

$\beta_{3} A R-D O G$

$\beta_{3} A R-P I C$

$\beta_{3}$ AR-HUMAN

$\beta_{3} \mathrm{AR}-\mathrm{MACACA}$

$\beta_{3}$ aAR-MOUSE

$\beta_{3}$ bAR-MOUSE

$\beta_{3}$ AR-DOG

$\beta_{3}$ AR-PIG

$B_{3}$ AR-HUMAN

$\beta_{3}$ AR-MACACA

$\beta_{3}$ aAR-MOUSE B, BAR-MOUSE

$\beta_{3} A R-D O G$

$B_{3}$ AR-PIG

$\beta_{3}$ AR-HUMAN

$\beta_{3}$ AR-MACACA

$\beta_{3}$ aAR-MOUSE

$\beta_{3}$ bAR-MOUSE

$\beta_{3}$ AR-DOG

$\beta_{3} A R-P I G$

$\beta_{3}$ AR-HUMAN

$B_{3} \mathrm{AR}-\mathrm{MACACA}$

FIGURE 2. Multiple alignment of mammalian $\beta_{3}$ AR. Protein sequence alignment of mouse, dog, pig, human, and Macaca mulatta $\beta_{3} \mathrm{AR}$. The TMD is highlighted in yellow; the tryptophan (W) in position 64 is in red; the cysteine (C) in position 361 is in green. $\beta_{3}$ aAR-MOUSE

$\beta_{3}$ bAR-MOUSE

$\beta_{3} \mathrm{AR}-\mathrm{DOG}$

$\beta_{3} A R-P I G$

$\beta_{3} A R-H U M A N$

$\beta_{3} \mathrm{AR}-\mathrm{MACACA}$
1 MAPWPHRNGSLALWSDAPTLDPSAANTSGLPGVPWAAALAGALLA---IATVGGNLLVII 57

1 MAPWPHRNGSLALWSDAPTLDPSAANTSGLPGVPWAAALAGALLA---LATVGGNLLVII 57

1 MAPWPHGNGSVASWPAAPTPTPDAANTSGLPGAPWAVALAGALLALEVLATVGGNLLVIV 60

1 MAPWPQGNSSLPPRPDVSTLAPNTANTSGLPGVPWAVALAGALLAPAVLATVGGNLLVIV 60

1 MAPWPHENSSLAPWPDLPTLAPNTANTSGLPGVPWEAALAGALLALAVLATVGGNLLVIV 60

1 MAPWPHGNSSLVPWPDVPTLAPNTANTSGLPGVPWAAALAGALLALAVLATVGGNLLVIV 60

TMD2

TMD3

58 AIARTPRLQTITNVEVTSLAAADLVVGLLVMPPGATLALTGHWPLGETGCELWTSVDVLC 117

58 AIARTPRLQTITNVEVTSLAAADLVVGLLVMPPGATLALTGHWPLGETGCELWTSVDVLC 117

61 AIARTPRLQTMTNVEVTSLATADLVVGLLVVPPGATLALTGRWPLGATGCELWTSVDVLC 120

61 AIARTPRLQTMTNVEVTSLATADLVVGLLVVPPGTTLALTGHWPLGATCCELWTSVDVLC 120

61 AIAWTPRLQTMTNVFVTSLAAADLVMGLLVVPPAATLALTGHWPLGATGCELWTSVDVLC 120

61 AITRTPRLQTMTNVEVTSLAAADLVMGLLVVPPAATLVLTGHWPLGATGCELWTSVDVLC 120

TMD 4

118 VTASIETLCALAVDRYLAVTNPLRYGTLVTKRRARAAVVLVWIVSAAVSFAPIMSQWWRV 177 118 VTASIETLCAIAAVDRYLAVTNPLRYGTLVTKRRARAAVVLVWIVSAAVSFAPIMSQWWRV 177

121 VTASIETLCALAVDRYLAVTNPLRYGALVTKRRARAAVVLVWVVSAAVSFAPIMSKWWRV 180

121 VTASIETLCALAVDRYLAVTNPLRYGALVTKRRARAAVVLVWVVSAAVSFAPIMSKWWRV 180

121 VTASIETLCALAVDRYLAVTNPLRYGALVTKRCARTAVVLVWVVSAAVSFAPIMSQWWRV 180

121 VTASIETLCALAVDRYLAVTNPLRYGALVTKRRARAAVVLVWVVSAAVSFAPIMS QWWRV 180

TMD5

178 GADAEAOECHSNPRCCSFASNMPYALTSSSVSFYLPLLVMLFVYARVFVVAKRQRHLLRR 237

178 GADAEAQECHSNPRCCSFASNMPYALLSSSVSFYLPLLVMLFVYARVFVVAKRQRHLLRR 237

181 GADAEAQRCHSNPHCCAFASNIPYALISSSVSFYLPLLVMLFVYARVFLVATRQLRLLRR 240

181 GADAEAQRCHSNPSCCTFASNMPYALISS SVSFYLPLLVMLFVYARVFVVATSQLRLLRW 240

181 GADAEAQRCHSNPRCCAFASNMPYVLLSSSVSFYLPLLVMLFVYARVFVVATRQLRLLRG 240

181 GADAEAORCHSNPRCCAFASNMPYVLLSSSVSFYLPLLVMLFVYARVFVVATRQLRLLRW 240

TMD6

238 ELGRFSPEESPPSPSRSPPATGGTPAAPDGVPPCGRRPARLLPLREHRALRTLGLIMGI 297

238 ELGRESPEESPPSPSRSPSPATGTPAAPDGVPPCGRRPARLLPLREHRALRTLGLIMGI 297

241 ELGRFPPAESPPAASRSRSPGPARRCASPAAVPSDRLRPARLLPLREHRALRTLGLIVGT 300

241 ELNRFPPEESPPAPSRSQSPAPGQPWPSPAGVPSHGRRPARLLPLREHRALCTLGLIMGT 300

241 ELGREPPEESPPAPSRSLAPAPVGTCAPPEGVPACGRRPARLLPLREHRALCTLGLIMGT 300

241 ELGRFPPEESSPALSRSLAPAPAGTCAPPEGVPACCRRPARLLPLREHRALCTLGLIMGT 300

TMD 7

298 FSLCWLPFFLANVLRALAGPSLVPSGVFIALNWLGYANSAFNPVIYCRSPDERDAFRRLL 357 298 FSLCWLPFFLANVLRALAGPSLVPSGVFIALNWLGYANSAFNPVIYCRSPDFRDAFRRLL 357

301 FTLCWLPFFVANVMRALGGPSLVPSPALLALNWLGYANSAFNPLIYCRSPDERSAFRRLL 360

301 FTLCWLPFFVVNVVRALGGPSLVPVPAFLALNWLGYANSAFNPLIYCHSPDFRSAFRRLL 360

301 FTLCWLPFFLANVLRALGGPSLVPGPAFLALNWLGYANSAFNPLIYCRSPDFRSAFRRLL 360

301 FTLCWLPFFLANVLRALGGPSLVPDPAFLALNWLGYANSAFNPLIYCRSPDERSAFRRLL 360
358 CSYGGRGPEEPRAVTFPASPVEARQSPPLNREDGYEGARPFPT-------------- 400

358 CSYGGRGPEEPRAVTEPASPVEARQSPPLNSSLLREPRHLYTCLGYP------------ 404

361 CRCRREE---HRAAASPPGDPSAAPA---A---LTSPAESSRCQALDGASWGIS------ 405

361 CRCGPEE---HLAAASPPRAPSGAPE---T---LTHPAESRQSPPLDEASWGLFRP---- 407

361 CRCGRRLPPEPCAAARPALEPSGVPA---A---RSSPAQPRLCQRLDGASWGVS------ 408

361 CHCGGRLPREPCAADRPASSPRAPLR---P---GPAPRSPGEASGSTGLLGEFLRPEGQE 414 permeability transition pore that is a cause of cell death. ${ }^{30-32}$ Of note, both these phenomena occur during reperfusion of ischemic myocardium and can lead to progression toward heart failure $(\mathrm{HF}){ }^{30-32}$

Pertaining to specific species differences of the $\beta_{3} \mathrm{AR}$, humans have a natural mutation. In fact, there is a nonsynonymous polymorphism at amino acid 64 where a tryptophan can exist instead of arginine (Figs. 1, 2). This mutation makes the $\beta_{3}$ AR less responsive to catecholamine stimulation, ${ }^{33}$ which has been associated with some pathophysiological conditions (ie, obesity) ${ }^{34,35}$ (Box 1). This important difference suggests that nonhuman $\beta_{3} \mathrm{AR}$ and its signaling may not fully mirror the human system. 
BOX 1. Pathologies Associated With $\beta_{3}$ AR-Trp64Arg Polymorphism

1. Obesity, susceptibility to

2. Diabetes

3. Insulin resistance

4. Hyperuricemia

\section{The $\beta_{3} A R$ in Cardiac Disease}

Accumulating evidence has revealed that the $\beta_{3} \mathrm{AR}$, present in endothelium and myocardium, may have specific beneficial effects in the cardiovascular system including cardioprotection. ${ }^{26}$ This becomes critically crucial in cardiac diseases such as HF, a syndrome characterized by decreased cardiac output, caused by deficits in contractility and/or relaxation. Importantly, after an injury such as ischemia, to preserve cardiac output, there is an increase in sympathetic activity and in catecholamine release to stimulate $\beta A R$ mediated inotropic capacity. However, chronic exposure of the heart to high levels of catecholamines can lead to further pathologic changes in the heart that can induce a progressive deterioration of cardiac function and structure. Of note, catecholamines directly stimulate $\beta$ ARs, and the sustained activation of these receptors correlate with left ventricular (LV) dysfunction and mortality. ${ }^{36}$ In this regard, GRK2, the principal GRK involved in $\beta$ AR regulation within the cardiomyocytes, phosphorylates the receptors attenuating their increased responsiveness. ${ }^{4}$ This process, called desensitization, at early stage represents a protective mechanism, but in chronic stage can cause $\beta_{1}$ and $\beta_{2}$ ARs dysregulation and signaling abnormalities (eg, downregulation and overdesensitization) and promote the progression of the disease. ${ }^{4}$ Importantly, as discussed above, $\beta_{3}$ ARs lack GRK recognition sites and are not subject to desensitization and downregulation, and in fact, their levels within human failing myocardium remain unchanged ${ }^{37}$ or become upregulated. ${ }^{38}$ Enhancement of $\beta_{3}$ ARs could represent either a protective mechanism against the detrimental effects of chronic $\beta A R$ stimulation or a detrimental mechanism that may lead to further deterioration of HF. In this regard, the role of this receptor in the heart has been debated for years, and some reports have suggested that due to its cardiodepressant effect, sustained activation of $\beta_{3}$ ARs in HF could contribute to impaired cardiac function. ${ }^{39}$ Consistently, the antagonism of this receptor has been proposed as a potential strategy against HF development. ${ }^{39,40}$ However, by contrast with this hypothesis, it has been demonstrated that in the failing myocardium, $\beta_{3}$ ARs are able to inhibit, through activation of $\mathrm{Na}^{+}-\mathrm{K}^{+}$pump, the deleterious accumulation of $\mathrm{Na}^{+}$in cardiac myocytes ${ }^{41,42}$ thus blocking cAMP generation, ${ }^{43}$ and consequently, reducing the activation of the cAMPdownstream oxidative pathways. Mechanistically, this effect decreases the glutathionylation of the $\beta_{1} \mathrm{Na}^{+}-\mathrm{K}^{+}$pump subunit and enhances the $\mathrm{Na}^{+}-\mathrm{K}^{+}$pump activity in presence of $\beta_{3}$ AR agonists. ${ }^{43}$
In line with the notion that $\beta_{3} \mathrm{AR}$ activation in failing myocardium is not detrimental, studies strongly support the idea that overexpression or persistent activation of $\beta_{3} \mathrm{AR}$ is cardioprotective and can attenuate pathological LV hypertrophy induced by continuous infusion of isoproterenol and angiotensin II, or by transaortic constriction, in mice. ${ }^{44,45}$ Importantly, as shown in these studies, the activation of NOS and subsequent NO generation represent the main mechanism responsible for $\beta_{3} \mathrm{AR}$-induced cardioprotection. In agreement with this mechanism of action, another study, using small (mice) and large (pigs) animal models of ischemia/reperfusion (I/R) injury, demonstrated that administration of selective $\beta_{3} \mathrm{AR}$ agonist BRL 37344 positively affected infarct size (acutely) and LV function (chronically). ${ }^{46}$ Further, this study showed that $\beta_{3} \mathrm{AR} / \mathrm{NO}$ signaling decreased opening of the mitochondrial permeability transition pore, thus conferring protection to the cardiac cells against cell death. ${ }^{46}$ Finally, it is well established that the role of exercise in cardioprotection, ${ }^{47}$ and $\beta_{3}$ ARs, has been also shown to be a mediator of this effect, ${ }^{48}$ especially in a setting of cardiac $\mathrm{I} / \mathrm{R}$ injury. ${ }^{48}$ Of note, during exercise, it seems that $\mathrm{G} \alpha \mathrm{s}$ is the key mediator of $\beta_{3} \mathrm{AR}$-induced protection that leads to the PKA/Akt/eNOS activation, thus suggesting that, in some conditions, the $\beta_{3} \mathrm{AR}$, similarly to the cardioprotective $\beta_{2} \mathrm{AR},{ }^{49}$ is coupled with both $\mathrm{G} \alpha \mathrm{s}$ and $\mathrm{G} \alpha \mathrm{i}$ in cardiomyocytes (Fig. 4). In this regard, this signaling pathway activation has a multiple protective role in the injured myocardium like the promotion of revascularization of the ischemic tissue. In fact, activation of Akt and eNOS, and the consequent secretion of NO, has been proven to directly stimulate endothelial cell function and promote the neoangiogenesis. ${ }^{50}$ Further, as discussed above, the eNOS-mediated generation of NO is also responsible for cGMP and PKG activation, thus directly conferring beneficial effects on the myocardium. ${ }^{51}$

\section{$\beta$-Blockers and $\beta_{3}$ ARs}

As described above, $\beta_{3}$ ARs have emerged as novel potential targets for the treatment of certain cardiovascular diseases including HF. The clinical relevance of this is further supported by the successful effects obtained with $\beta$-blocker treatment in patients with HF as they can block the noxious effects of catecholamines and prevent further $\beta_{1}$ and $\beta_{2}$ ARs downregulation. ${ }^{4}$ Importantly, as proposed by us and others, the use of $\beta$-blockers may influence the expression/activity of $\beta_{3}$ ARs. ${ }^{35,52,53}$ However, because there are some specific differences in $\beta$-blockers ( $\beta_{1} \mathrm{AR}$ selective or nonselective), the full extent of whether any molecular changes in $\beta_{3}$ ARs are significant contributors to the therapeutic mechanisms of $\beta$ AR antagonism in HF still remains to be elucidated. Accordingly, answering these mechanistic questions is important and may lead to novel therapeutic advances in HF.

In 2007, it was first reported that a relationship between $\beta$-blockers and $\beta_{3} \mathrm{AR}$ may exist. ${ }^{54}$ In particular, in an HF rat model induced by transaortic constriction, it has been shown that, although metoprolol (a selective $\beta_{1}$-blocker) treatment did not affect the expression levels of $\beta_{3} \mathrm{AR}$ which was increased after HF, the use of carvedilol (a nonselective $\beta$-blocker) resulted in a robust $\beta_{3}$ AR downregulation. ${ }^{54} \mathrm{Nev}$ ertheless, soon after this report, a number of studies proposed 


\begin{abstract}
$\beta_{3} \mathrm{AR} \quad 1-------M A P W P H E N S S L A P W P D L P-------------T L A P N T A N T S G L P G V P W E A A \quad 38$
$\beta_{1}$ AR 1 MGAGVLVLGASEPGNLSSAAPLPDGAATAARLLVPASPPASLLPPASESPEPLSQQWTA- 59

$\beta_{2} \mathrm{AR} \quad 1---------M G Q P G N G S------------A F L L A----$ PNRSHAPDHDVTQQRDEVWVV- 34

TMD1 TMD2

$\beta_{3} A R \quad 39$ LAGALLALAVLATVGGNLLVIVAIAWTPRLQTMTNVFVTSLAAADLVMGLLVVPPAATLA 98

$\beta_{1} A R \quad 60$ GMGLLMALIVLLIVAGNVLVIVAIAKTPRLQTLTNLFIMSLASADLVMGLLVVPFGATIV 119

$\beta_{2} A R \quad 35$ GMGIVMSLIVLAIVFGNVLVITAIAKFERLQTVTNYFITSLACADLVMGLAVVPFGAAHI 94

TMD3

TMD4

$\beta_{3}$ AR 99 LTGHWPLGATGCELWTSVDVLCVTASIETLCALAVDRYLAVTNPLRYGALVTKRCARTAV 158

$\beta_{1} A R \quad 120$ VWGRWEYGSFFCELWTSVDVLCVTASIETLCVIALDRYLAITSPFRYQSLLTRARARGLV 179

$\beta_{2} A R \quad 95$ LMKMWTFGNFWCEFWTSIDVLCVTASIETLCVIAVDRYFAITSPFKYQSLLTKNKARVII 154

TMD5

$\beta_{3} A R \quad 159$ VLVWVVSAAVSFAPIMSQWWRVGADAEAQRCHSNPRCCAFASNMPYVLLSSSVSFYLPLL 218

$\beta_{1} A R \quad 180$ CTVWAISALVSFLPILMHWWRAES-DEARRCYNDPKCCDFVTNRAYAIASSVVSFYVPLC 238

$\beta_{2} A R \quad 155$ LMVWIVSGLTSFLPIQMHWYRATH-QEAINCYANETCCDFFTNQAYAIASSIVSFYVPLV 213
\end{abstract}

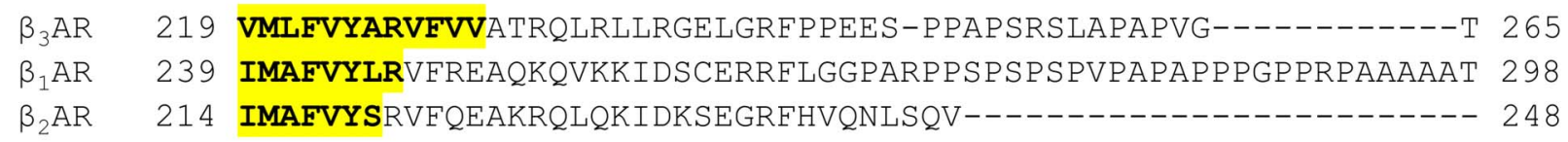

$\begin{array}{ccc} & \text { TMD6 } \\ \beta_{3} \mathrm{AR} & 266 & \text { CAPPEGVPACGRRPARLLPLREHRALCTLGLIMGTFTLCWLPFFLANVLRALGGPSLVPG } 325 \\ \beta_{1} \mathrm{AR} & 299 & \text { APLANGRAG-KRRPSRLVALREQKALKTLGIIMGVFTLCWLPFFLANVVKAFH-RELVPD } 356 \\ \beta_{2} \mathrm{AR} & 249 & \text {--EQDGRTGHGLRRSSKFCLKEHKALKTLGIIMGTFTLCWLPFFIVNIVHVIQ-DNLIRK } 305\end{array}$

TMD7

$\beta_{3} A R \quad 326$ PAFLALNWLGYANSAFNPLIYCRSPDFRSAFRRLLCRCGRRLPPEPCAAARP--ALFPSG 383

$\beta_{1} A R \quad 357$ RLEVFFNWLGYANSAFNPIIYCRSPDFRKAFQGLLCCARRAARRRHA---THGDRPRASG 413

$\beta_{2} A R \quad 306$ EVYILLNWIGYVNSGFNPLIYCRSPDFRIAFQELLCLRRSSLKAYGNGYSSNGNTGEQSG 365

$\beta_{3} A R \quad 384$ VPAARSSPAQP----------RLCQR--------LDGASWGVS----------------408

$\beta_{1} A R \quad 414$ CLARPGPPPSPGAASDDDDDDVVGATPPARLLEPWAGCNGGAAADSDSSLDEPCRPGFAS 473

$\beta_{2} A R \quad 366$ YHVEQ-----------EKENKLLCEDLP--GTEDFVGHQGTVPSDNIDSQGRNCSTND-- 410

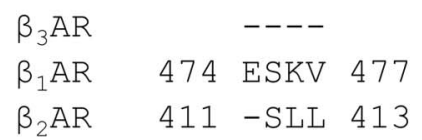

FIGURE 3. Multiple alignment of human $\beta$ ARs. Protein sequence alignment of human $\beta_{1}, \beta_{2}$, and $\beta_{3}$ AR. The TMD is highlighted in yellow.

that $\beta_{1}$-blockers and their subsequent beneficial effects in HF could induce enhancement of the $\beta_{3}$ AR expression and activity. For example, Sharma et $\mathrm{al}^{53}$ showed that metoprolol treatment was able to improve cardiac function in diabetic rats mainly through $\beta_{3} \mathrm{AR}$ upregulation and $\mathrm{NO}$ generation. Analogous, in a canine model of mitral regurgitation, we recently found that metoprolol can promote $\beta_{3} \mathrm{AR}$ upregulation and enhance its protective signaling (ie, nNOS/NO/ cGMP). ${ }^{25}$ Moreover, correlative data have been recently shown for the potential of $\beta_{3} \mathrm{AR}$ agonistic activity of nebivolol, a highly selective $\beta_{1}$-blocker. ${ }^{52,55}$ In particular, in a model of $\mathrm{I} / \mathrm{R}$ injury, nebivolol administration activated cardiac 
FIGURE 4. Schematic representation of $\beta_{3} A R$ signaling activation in cardiomyocytes. $\beta_{3}$ ARs are coupled to both stimulatory $G$ proteins (Gs) and inhibitory $\mathrm{G}$ proteins (Gi). Although the Gs pathway induces the generation of CAMP and CGMP which, in turn, activates the PKA and PKG, respectively, the activation of $\mathrm{Gi}$ signaling pathway is able to stimulate only the generation of CGMP and the activation of PKG. PKA has multiple roles in cardiomyocytes and is able to induce the phosphorylation of several key factors involved in the regulation of contractility, such as cardiac troponin I (cTnl) and phospholamban (PLN). The latter affects $\mathrm{Ca}^{2+}$ cycling to the contractile proteins. Furthermore, PKA can phosphorylate the L-type $\mathrm{Ca}^{2+}$ channel (LTCC) increasing the influx of extracellular $\mathrm{Ca}^{2+}$. Importantly, PKA can also activate protein kinase B (Akt) with the subsequent activation of the endothelial NO synthase (eNOS). Of note,

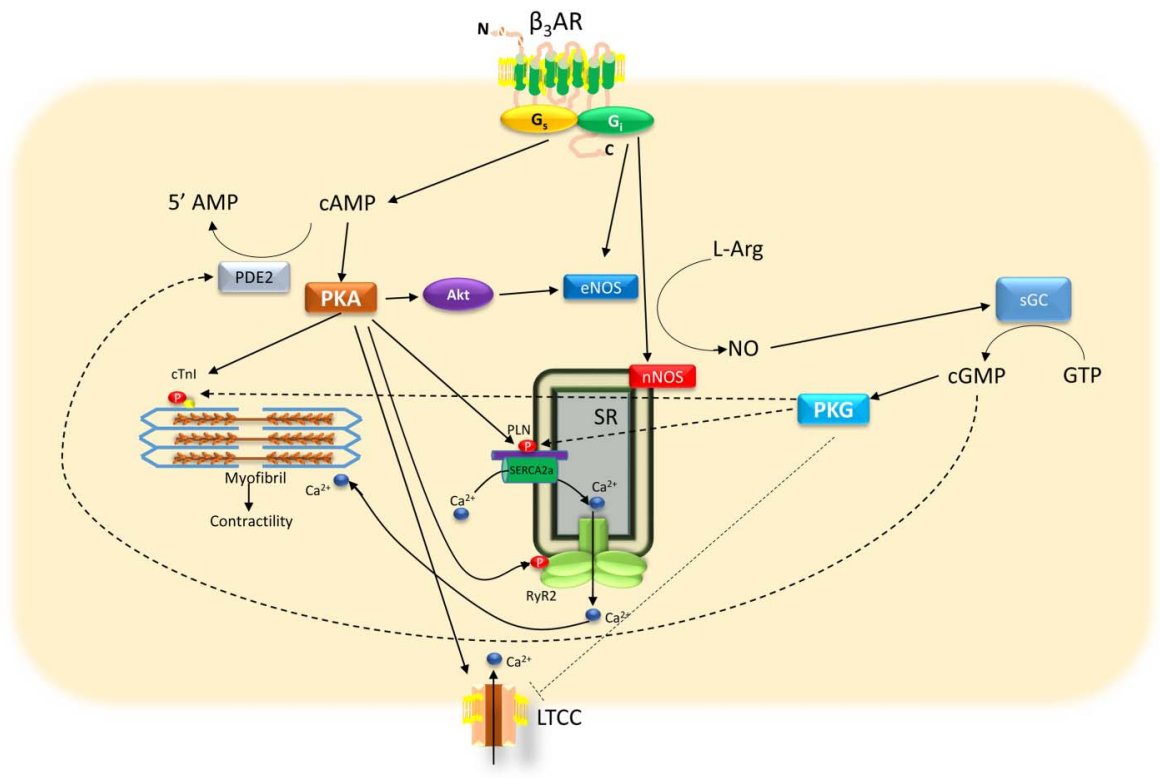
eNOS activation increases the generation of NO which, in turn, activates the soluble guanylate cyclase to produce cGMP and PKG activation. Similar to PKA, PKG is able to phosphorylate PLN and cTnl. However, PKG can induce the inactivation of LTCC, thus reducing the extracellular $\mathrm{Ca}^{2+}$ influx. Moreover, cGMP can stimulate phosphodiesterase 2 (PDE2), reducing the cAMP levels and the activation of PKA. Of note, after the Gi signaling pathway activation, the $\beta_{3} \mathrm{AR}$ is able to give rise to NO through both eNOS and neuronal NOS (nNOS) located on the sarcoplasmic reticulum (SR).

$\beta_{3}$ ARs leading to a significant reduction of infarct size. ${ }^{55}$ Similarly, Zhang et al ${ }^{52}$ demonstrated, in a setting of HF in mice, induced by left anterior descending artery ligation, that nebivolol was able to reduce cardiac fibrosis and apoptosis and improved cardiac function. Interestingly, this report showed also that after 4 weeks postmyocardial infarction, there was a significant reduction of cardiac $\beta_{3} \mathrm{AR}$ levels, and that nebivolol was able to restore the expression of this receptor. ${ }^{52}$

Importantly, further to the direct effect in cardiomyocytes, $\beta_{1}$-blockers, such as nebivolol have been also reported to act on endothelium. ${ }^{56,57}$ Of note, enhancement of neoangiogenesis in the failing heart is considered one of the mechanisms of protection activated by this class of drugs. ${ }^{58}$ In this context, nebivolol through $\beta_{3} \mathrm{AR}$ activation increases the generation of $\mathrm{NO}$, a key mediator of endothelial function, ${ }^{50}$ enhancing endothelial proliferation and increasing vasodilation. ${ }^{56,57}$

\section{Clinical Perspectives of $\beta_{3}$ AR Receptor Targeting}

As described above, the $\beta_{3} \mathrm{AR}$ represents an emerging attractive target for pharmacological modulation in the injured heart that, for its compensatory effects, prevents the effects of excessive catecholamines stimulation on the heart. ${ }^{43,44}$ In fact, selective $\beta_{3} \mathrm{AR}$ agonism has been proven to confer protection in the failing heart through a specific cGMP/NO signaling pathway. ${ }^{26} \mathrm{~A}$ particular role for NO has been associated with the enhancement of endothelial cell proliferation, ${ }^{50}$ and within failing myocardium it can lead to a beneficial effect on cardiac function and remodeling. ${ }^{57,58}$ As described above, $\beta_{3}$ ARs are expressed not only in cardiomyocytes but also in endothelial cells, thus supporting the idea that this receptor can also promote proangiogenic mechanisms. ${ }^{9,56,57}$ Moreover, in adipocytes, the $\beta_{3} \mathrm{AR}$ is implicated in metabolic regulation [fatty acid (FA) oxidation, lipolysis, and thermogenesis], ${ }^{59}$ that can also be a crucial mechanism to rescue the heart from failure. Importantly, this mechanism is particularly important in several pathological conditions that affect cardiac function, such as ischemia and pressure overload. ${ }^{60}$ In fact, in these conditions, the heart, in the presence of limited oxygen supply, suppresses glucose and FA oxidation with a shift in cardiac substrate metabolism from FA oxidation to glycolysis. ${ }^{61}$ Glycolysis without a concomitant increase in glucose oxidation results in an accumulation of different harmful catabolites such as lactate and protons that are the cause of intracellular acidosis and $\mathrm{Na}^{+}$and $\mathrm{Ca}^{2+}$ overload. ${ }^{62}$ These effects strongly reduce the capacity of the heart to provide sufficient energy for contractile work because more energy is spent to restore ion homeostasis and lead to an increase in lipid accumulation within the cardiac cells with consequent lipotoxicity. ${ }^{61}$

In this context, as recently demonstrated in adipocytes, nebivolol, through $\beta_{3} \mathrm{AR}$ activation, is able to improve adipocyte metabolism. ${ }^{63}$ Therefore, it is plausible that longterm $\beta_{3} \mathrm{AR}$ stimulation, through selective agonists and/or $\beta$-blockers (ie, nebivolol), can be used as a novel therapeutical approach also to improve metabolism within the failing myocardium.

Currently, 2 clinical trials, the Beta 3 Agonist Treatment in Heart Failure (Beat-HF; clinicaltrials.gov: NCT01876433), or in the prevention of HF development, the Assessment of Efficacy of Mirabegron, a New Beta 3-adrenergic Receptor in the Prevention of Heart Failure (Beta3_LVH; clinicaltrials.gov: NCT02599480), are trying to evaluate the effects of $\beta_{3} \mathrm{AR}$ agonism on HF progression and development. 
In this context, patients will be treated with the selective $\beta_{3} \mathrm{AR}$ agonist, mirabegron (also known as YM-178), a drug already approved in the United States, Japan, and Europe, for the treatment of overactive bladder. ${ }^{64}$ This drug, through the activation of $\beta_{3} \mathrm{AR}$, exerts a myorelaxant effect in the detrusor muscle thus improving the bladder filling. These trials have recently started, so no results are available yet. Anyway, in the meantime that these trials will give us the proof-ofconcept of the beneficial role of $\beta_{3}$ ARs in human HF, the most important clinical evidence that we currently have regarding the role of this receptor remains the proved efficacy of $\beta$-blockers. The cardioprotective effect of $\beta$ AR-blockade has been largely attributed, for decades, to antagonism of cardiac $\beta_{1}$ and $\beta_{2}$ ARs and a resulting heart rate reduction. ${ }^{65}$ However, as discussed above in this review, there is emerging evidence that this class of drugs may also act through $\beta_{3}$ AR signaling pathway activation which is not blocked by the drugs currently used in clinical HF-therapy (Box 2). However, the main question that still remains unanswered is why not all patients respond favorably to these agents. For these reasons, further elucidation on specific mechanisms of action of these drugs is extremely interesting. ${ }^{2}$ In particular, it will be important to evaluate how different $\beta$-blockers can impact, in a positive or a negative manner, $\beta_{3} \mathrm{AR}$ activity, and if this effect is a significant contributor of therapeutic mechanisms in HF.

\section{BOX 2. $\beta$-blockers and $\beta_{3} \mathrm{AR}$ Expression/Activity}

1. Both metoprolol and nebivolol enhance $\beta_{3} \mathrm{AR}$ expression and activity.

2. Carvedilol reduces the expression of $\beta_{3} \mathrm{AR}$.

\section{CONCLUSIONS}

The $\beta_{3} \mathrm{AR}$ is a novel and intriguing receptor, with multiple functions within the cardiovascular system. In this review, we have discussed how many disparities have been generated around the signaling and the function of this receptor. However, the emerging concept in the literature is that $\beta_{3} \mathrm{AR}$ is mostly protective for the cardiovascular system and its agonism with selective ligands or activation during $\beta_{1}$ - and $\beta_{2}$ AR blockade could represent a future therapeutic strategy to prevent development of HF. Anyway, as discussed above, the $\beta_{3} \mathrm{AR}$ function in the heart is still poorly investigated, and for this reason, further investigations are required to clarify the causal mechanistic relationship between $\beta_{3} \mathrm{AR}$ expression and cardiac dysfunction and protection. More importantly, since presently, only $\beta_{1}$ ARblockers have been associated with improvement of the $\beta_{3} \mathrm{AR}$ signaling pathway, it will be crucial to define the specific signaling pathways associated with $\beta$-blockerdependent activation/inhibition of $\beta_{3}$ ARs because it can help in personalizing anti-HF therapy.

\section{REFERENCES}

1. Lin HH. G-protein-coupled receptors and their (bio) chemical significance win 2012 Nobel Prize in Chemistry. Biomed J. 2013;36:118-124.
2. Port JD, Bristow MR. Altered beta-adrenergic receptor gene regulation and signaling in chronic heart failure. J Mol Cell Cardiol. 2001;33:887905 .

3. Bristow MR. Changes in myocardial and vascular receptors in heart failure. J Am Coll Cardiol. 1993;22(4 suppl A):61A-71A.

4. Cannavo A, Liccardo D, Koch WJ. Targeting cardiac $\beta$-adrenergic signaling via GRK2 inhibition for heart failure therapy. Front Physiol. 2013:4:264.

5. Frielle T, Collins S, Daniel KW, et al. Cloning of the cDNA for the human beta 1-adrenergic receptor. Proc Natl Acad Sci U S A. 1987;84: 7920-7924.

6. Kobilka BK, Dixon RA, Frielle T, et al. cDNA for the human beta 2-adrenergic receptor: a protein with multiple membrane-spanning domains and encoded by a gene whose chromosomal location is shared with that of the receptor for platelet-derived growth factor. Proc Natl Acad Sci U S A. 1987;84:46-50.

7. Emorine LJ, Marullo S, Briend-Sutren MM, et al. Molecular characterization of the human beta 3-adrenergic receptor. Science. 1989;245: $1118-1121$

8. Simard PM, Atgie C, Mauriege P, et al. Comparison of the lipolytic effects of norepinephrine and BRL 37344 in rat brown and white adipocytes. Obes Res. 1994;2:424-431.

9. Dessy C, Balligand JL. Beta3-adrenergic receptors in cardiac and vascular tissues emerging concepts and therapeutic perspectives. Adv Pharmacol. 2010;59:135-163.

10. Skeberdis VA. Structure and function of beta3-adrenergic receptors. Medicina (Kaunas). 2004;40:407-413.

11. Moffett S, Mouillac B, Bonin H, et al. Altered phosphorylation and desensitization patterns of a human b2 -adrenergic receptor lacking the palmitoylated Cys341. EMBO J. 1993;12:349-356.

12. Hutchinson DS, Chernogubova E, Dallner OS, et al. Beta-adrenoceptors, but not alpha-adrenoceptors, stimulate AMP-activated protein kinase in brown adipocytes independently of uncoupling protein-1. Diabetologia. 2005;48:2386-2395.

13. Dessy C, Moniotte S, Ghisdal P, et al. Endothelial beta3-adrenoceptors mediate vasorelaxation of human coronary microarteries through nitric oxide and endothelium-dependent hyperpolarization. Circulation. 2004; 110:948-954.

14. Gauthier C, Langin D, Balligand JL. Beta3-adrenoceptors in the cardiovascular system. Trends Pharmacol Sci. 2000;21:426-431.

15. Imbrogno S, Gattuso A, Mazza R, et al. $\beta 3$-AR and the vertebrate heart: a comparative view. Acta Physiol (Oxf). 2015;214:158-175.

16. Evans BA, Papaioannou M, Hamilton S, et al. Alternative splicing generates two isoforms of the $\beta 3$-adrenoceptor which are differentially expressed in mouse tissues. Br J Pharmacol. 1999;127:1525-1531.

17. Hutchinson DS, Bengtsson T, Evans BA, et al. Mouse beta 3a- and beta 3b-adrenoceptors expressed in Chinese hamster ovary cells display identical pharmacology but utilize distinct signalling pathways. Br J Pharmacol. 2002; 135:1903-1914.

18. Sato M, Hutchinson DS, Bengtsson T, et al. Functional domains of the mouse beta3-adrenoceptor associated with differential $\mathrm{G}$ protein coupling. J Pharmacol Exp Ther. 2005;315:1354-1361.

19. Gerhardt CC, Gros J, Strosberg AD, et al. Stimulation of the extracellular signal-regulated kinase $1 / 2$ pathway by human beta-3 adrenergic receptor: new pharmacological profile and mechanism of activation. Mol Pharmacol. 1999;55:255-262.

20. Soeder KJ, Snedden SK, Cao W, et al. The beta3-adrenergic receptor activates mitogen-activated protein kinase in adipocytes through a Gi-dependent mechanism. J Biol Chem. 1999;274:12017-12022.

21. Gauthier C, Leblais V, Kobzik L, et al. The negative inotropic effect of beta3-adrenoceptor stimulation is mediated by activation of a nitric oxide synthase pathway in human ventricle. J Clin Invest. 1998;102: $1377-1384$

22. Gauthier C, Tavernier G, Charpentier F, et al. Functional beta3-adrenoceptor in the human heart. $J$ Clin Invest. 1996;98:556-562.

23. Bristow MR, Hershberger RE, Port JD, et al. Beta-adrenergic pathways in nonfailing and failing human ventricular myocardium. Circulation. 1990;82(2 suppl):I12-I25.

24. Brixius K, Bloch W, Pott C, et al. Mechanisms of $\beta 3$-adrenoceptorinduced eNOS activation in right atrial and left ventricular human myocardium. Br J Pharmacol. 2004;143:1014-1022. 
25. Trappanese DM, Liu Y, McCormick RC, et al. Chronic $\beta 1$-adrenergic blockade enhances myocardial $\beta 3$-adrenergic coupling with nitric oxidecGMP signaling in a canine model of chronic volume overload: new insight into mechanisms of cardiac benefit with selective $\beta 1$-blocker therapy. Basic Res Cardiol. 2015;110:456.

26. Balligand JL. Cardiac salvage by tweaking with beta-3-adrenergic receptors. Cardiovasc Res. 2016;111:128-133.

27. Angelone T, Filice E, Quintieri AM, et al. Beta3-adrenoceptors modulate left ventricular relaxation in the rat heart via the NO-cGMP-PKG pathway. Acta Physiol (Oxf). 2008;193:229-239.

28. Tsai EJ, Kass DA. Cyclic GMP signaling in cardiovascular pathophysiology and therapeutics. Pharmacol Ther. 2009;122:216-238.

29. Takimoto E. Cyclic GMP-dependent signaling in cardiac myocytes. Circ J. 2012;76:1819-1825.

30. Abdallah Y, Gkatzoflia A, Pieper H, et al. Mechanism of cGMPmediated protection in a cellular model of myocardial reperfusion injury. Cardiovasc Res. 2005;66:123-131.

31. Abdallah Y, Gkatzoflia A, Gligorievski D, et al. Insulin protects cardiomyocytes against reoxygenation-induced hypercontracture by a survival pathway targeting SR Ca2+ storage. Cardiovasc Res. 2006;70:346-353.

32. Inserte J, Garcia-Dorado D. The cGMP/PKG pathway as a common mediator of cardioprotection: translatability and mechanism. $\mathrm{Br} J$ Pharmacol. 2015; 172:1996-2009.

33. Kimura K, Sasaki N, Asano A, et al. Mutated human beta3-adrenergic receptor (Trp64Arg) lowers the response to beta3-adrenergic agonists in transfected 3T3-L1 preadipocytes. Horm Metab Res. 2000;32:91-96.

34. Csernus K, Pauler G, Erhardt É, et al. Effects of energy expenditure gene polymorphisms on obesity-related traits in obese children. Obes Res Clin Pract. 2015;9:133-140.

35. Mirrakhimov AE, Kerimkulova AS, Lunegova OS, et al. An association between TRP64ARG polymorphism of the B3 adrenoreceptor gene and some metabolic disturbances. Cardiovasc Diabetol. 2011;10:89.

36. Bristow MR, Ginsburg R, Minobe W, et al. Decreased catecholamine sensitivity and beta-adrenergic-receptor density in failing human hearts. N Engl J Med. 1982;307:205-211.

37. Fischer V, Gabauer I, Tillinger A, et al. Heart adrenoceptor gene expression and binding sites in the human failing heart. Ann NY Acad Sci. 2008; 1148:400-408.

38. Moniotte S, Kobzik L, Feron O, et al. Upregulation of beta(3)adrenoceptors and altered contractile response to inotropic amines in human failing myocardium. Circulation. 2001;103:1649-1655.

39. Moniotte S, Balligand JL. Potential use of beta(3)-adrenoceptor antagonists in heart failure therapy. Cardiovasc Drug Rev. 2002;20:19-26.

40. Masutani S, Cheng HJ, Morimoto A, et al. $\beta 3$-Adrenergic receptor antagonist improves exercise performance in pacing-induced heart failure. $\mathrm{Am}$ J Physiol Heart Circ Physiol. 2013;305:H923-H930.

41. Bundgaard H, Liu CC, Garcia A, et al. $\beta(3)$ adrenergic stimulation of the cardiac $\mathrm{Na}+\mathrm{K}+$ pump by reversal of an inhibitory oxidative modification. Circulation. 2010;122:2699-2708.

42. Galougahi KK, Liu CC, Bundgaard H, et al. $\beta$-Adrenergic regulation of the cardiac $\mathrm{Na}+\mathrm{K}+$ ATPase mediated by oxidative signaling. Trends Cardiovasc Med. 2012;22:83-87.

43. Mongillo M, Tocchetti CG, Terrin A, et al. Compartmentalized phosphodiesterase-2 activity blunts beta-adrenergic cardiac inotropy via an NO/cGMP-dependent pathway. Circ Res. 2006;98:226-234.

44. Belge C, Hammond J, Dubois-Deruy E, et al. Enhanced expression of $\beta 3$-adrenoceptors in cardiac myocytes attenuates neurohormone-induced hypertrophic remodeling through nitric oxide synthase. Circulation. 2014;129:451-462.

45. Niu X, Watts VL, Cingolani OH, et al. Cardioprotective effect of beta-3 adrenergic receptor agonism: role of neuronal nitric oxide synthase. J Am Coll Cardiol. 2012;59:1979-1987.

46. García-Prieto J, García-Ruiz JM, Sanz-Rosa D, et al. $\beta 3$ adrenergic receptor selective stimulation during ischemia/reperfusion improves cardiac function in translational models through inhibition of $\mathrm{mPTP}$ opening in cardiomyocytes. Basic Res Cardiol. 2014;109:422.
47. Rengo G, Parisi V, Femminella GD, et al. Molecular aspects of the cardioprotective effect of exercise in the elderly. Aging Clin Exp Res. 2013;25:487-497.

48. Calvert JW, Condit ME, Aragón JP, et al. Exercise protects against myocardial ischemia-reperfusion injury via stimulation of $\beta(3)$-adrenergic receptors and increased nitric oxide signaling: role of nitrite and nitrosothiols. Circ Res. 2011;108:1448-1458.

49. Salazar NC, Vallejos X, Siryk A, et al. GRK2 blockade with $\beta$ ARKct is essential for cardiac $\beta 2$-adrenergic receptor signaling towards increased contractility. Cell Commun Signal. 2013;11:64.

50. Cannavo A, Liccardo D, Lymperopoulos A, et al. $\beta$ adrenergic receptor kinase $\mathrm{C}$-terminal peptide gene-therapy improves $\beta 2$-adrenergic receptordependent neoangiogenesis after hindlimb ischemia. J Pharmacol Exp Ther. 2016;356:503-513.

51. Walther S, Pluteanu F, Renz S, et al. Urocortin 2 stimulates nitric oxide production in ventricular myocytes via Akt- and PKA-mediated phosphorylation of eNOS at serine 1177. Am J Physiol Heart Circ Physiol. 2014;307:H689-H700.

52. Zhang Z, Ding L, Jin Z, et al. Nebivolol protects against myocardial infarction injury via stimulation of beta 3-adrenergic receptors and nitric oxide signaling. PLoS One. 2014;9:e98179.

53. Sharma V, Parsons H, Allard MF, et al. Metoprolol increases the expression of beta(3)-adrenoceptors in the diabetic heart: effects on nitric oxide signaling and forkhead transcription factor-3. Eur J Pharmacol. 2008; 595:44-51.

54. Zhao Q, Wu TG, Jiang ZF, et al. Effect of beta-blockers on beta3adrenoceptor expression in chronic heart failure. Cardiovasc Drugs Ther. 2007;21:85-90.

55. Aragón JP, Condit ME, Bhushan S, et al. Beta3-adrenoreceptor stimulation ameliorates myocardial ischemia-reperfusion injury via endothelial nitric oxide synthase and neuronal nitric oxide synthase activation. $J \mathrm{Am}$ Coll Cardiol. 2011;58:2683-2691.

56. Dessy C, Saliez J, Ghisdal P, et al. Endothelial beta3-adrenoreceptors mediate nitric oxide-dependent vasorelaxation of coronary microvessels in response to the third-generation beta-blocker nebivolol. Circulation. 2005; 112:1198-1205.

57. Sorrentino SA, Doerries C, Manes C, et al. Nebivolol exerts beneficial effects on endothelial function, early endothelial progenitor cells, myocardial neovascularization, and left ventricular dysfunction early after myocardial infarction beyond conventional $\beta 1$-blockade. J Am Coll Cardiol. 2011;57: 601-611.

58. Rengo G, Cannavo A, Liccardo D, et al. Vascular endothelial growth factor blockade prevents the beneficial effects of $\beta$-blocker therapy on cardiac function, angiogenesis, and remodeling in heart failure. Circ Heart Fail. 2013;6:1259-1267.

59. Suárez J, Rivera P, Arrabal S, et al. Oleoylethanolamide enhances $\beta$-adrenergic-mediated thermogenesis and white-to-brown adipocyte phenotype in epididymal white adipose tissue in rat. Dis Model Mech. 2014; 7:129-141.

60. Schulze PC, Drosatos K, Goldberg IJ. Lipid use and misuse by the heart. Circ Res. 2016;118:1736-1751.

61. Abdurrachim D, Luiken JJ, Nicolay K, et al. Good and bad consequences of altered fatty acid metabolism in heart failure: evidence from mouse models. Cardiovasc Res. 2015;106:194-205.

62. Depre C, Vanoverschelde JL, Taegtmeyer H. Glucose for the heart. Circulation. 1999;99:578-588.

63. Bordicchia M, Pocognoli A, D’Anzeo M, et al. Nebivolol induces, via $\beta 3$ adrenergic receptor, lipolysis, uncoupling protein 1 , and reduction of lipid droplet size in human adipocytes. J Hypertens. 2014;32:389-396.

64. Kashyap M, Tyagi P. The pharmacokinetic evaluation of mirabegron as an overactive bladder therapy option. Expert Opin Drug Metab Toxicol. 2013;9:617-627.

65. Heusch G. Heart rate in the pathophysiology of coronary blood flow and myocardial ischaemia: benefit from selective bradycardic agents. $\mathrm{Br} J$ Pharmacol. 2008;153:1589-1601. 